World Flash on Basic Research

\title{
INTERNATIONAL COLLABORATION OF THREE EAST EUROPEAN COUNTRIES WITH GERMANY IN THE SCIENCES, 1980-1989
}

\author{
W. GLÄNZEL, *+ M. WINTERHAGER *** \\ *University Bielefeld, Center for Science Studies, P.O.B. 8640, W-4800 Bielefeld 1 (Germany) \\ ** Social Sciences Information Centre, Lennéstraße 30, W-5300 Bonn 1 (Germany)
}

(Received January 14, 1992)

\section{Introduction}

In a recent study on international collaboration in the sciences, Schubert and Braun $^{1}$ have presented figures and indicators in order to characterize significance and strength of international research cooperation 1981-1985. Collaboration was measured through the number of co-authorship links. As a main result, Schubert and Braun presented a world map of international cooperative links in the sciences for the 36 most productive countries in the world. The links have been considered to be significant if Salton's measure $r_{i k}$, i.e., the ratio of the number of two countries' cooperations and the geometric mean of their total publication outputs, is greater than $1 \%$. In principle, the existence of four major co-author clusters of the map confirms some well-known facts, particularly, the intensive cooperation in the Western world represented by one huge cluster and two smaller ones (Nordic countries and Australia and New Zealand, respectively) and a separate smaller cluster for Eastern Europe. Somewhat surprising was, however, the significant link between Poland and Germany (cf. Schubert and Braun 1 ). This was in brief the situation in the first half of the decade.

\footnotetext{
+ On leave from: Information Science and Scientometrics Research Unit (ISSRU), Library of the Hungarian Academy of Sciences, P.O.B. 7, H-1361 Budapest, Hungary.
} 
Now, as a consequence of the political, economic and cultural changes in Eastern Europe, and especially with regard to the great effort of Hungary, Poland and Czechoslovakia towards a soon integration into the European Community an increasing interest on the research performance and the cooperative links of these countries has arisen. In the following we attempt to analyse the collaboration of these three countries with the EC countries, especially with Germany in the decade 19801989.

\section{Data sources}

All data used for the analysis have been taken from the $\mathrm{SCI}^{\circledR}$ and $\mathrm{SSCI}^{\circledR}$ databases of the Institute for Scientific Information (ISI, Philadelphia, PA, USA). Data have been retrieved based on the on-line version SCISEARCH ${ }^{\circledR}$ (via DIMDI), whereas particular information concerning the publication profile and the authors' affiliation have been taken from the CD-ROM version of the SCI ${ }^{\circledR}$. Citations have been calculated from the magnetic tapes of the annual cumulations Citation Index Files of the $\mathrm{SCI}^{\circledR}$ and in part based on SCISEARCH ${ }^{\circledR}$ (via DIMDI).

Only citable items (e.g., research articles, letters, notes, reviews) were taken into consideration. The papers have been assigned to countries based on the corporate address given by the authors. Co-authorship of Hungarian, Czechoslovakian and Polish authors with European authors has been recorded if the concerning countries occured simultaneously.

The annual number of publications have been retrieved for 1980-1989, citations were counted for the first three years, starting from the publication year. The choice of this citation window makes sure that the citation impact of all selected papers could be calculated. The size of all science paper sets was great enough to conduct reliable statistical analyses. On the other hand, the set of social science papers was not sufficiently large for any scientometric analysis. Only 34 co-authorships of the three countries with Germany were found for the whole decade. The following study is therefore restricted to five global fields of the sciences, particularly to the life sciences, physical sciences, chemistry, engineering and mathematics.

\section{Results}

Although the United Kingdom is with more than $30 \%$ of all papers published by EC countries in the sciences the greatest European scientific community (see Table 
1), co-operation with the analysed countries, especially with Hungary and Poland, is unambiguously dominated by German scientists. Table 1 presents the basic bibliometric data on the co-authorship links of Hungary, Poland and Czechoslovakia with the member states of the European Community. Some more interesting results can be obtained if the relative strength of co-authorship links is considered for the first and the second half of the decade, separately. In Table 2 Salton's measure has been used. Its exact definition is

$$
\mathrm{r}_{\mathrm{ik}}=\mathrm{n}_{\mathrm{ik}} /\left(\mathrm{n}_{\mathrm{i}} \mathrm{n}_{\mathrm{k}}\right)^{1 / 2}
$$

where $n_{i k}$ is the number of co-authored papers with addresses of two analysed countries and $n_{i}$ and $n_{k}$ is their total publication output. The strength of coauthorship links of Hungary, Poland and Czechoslovakia with almost all EC countries increases in the second half of the 1980s. The closest links can be found between Germany and these countries. Only in case of Czechoslovakia cooperation remains below the threshold value of $1 \%$. The cooperation between Polish and French authors during 1986 and 1989 is, however, remarkable.

Table 1

Distribution of the contribution to EC research output by member countries based on corporate addresses of publications (column 1) and distribution of East European co-authorship links with EC member countries (column 2-4)

\begin{tabular}{lrrrr}
\hline Country & EC & HUN & POL & CZE \\
\hline UK & 30.6 & 17.0 & 15.8 & 17.7 \\
Germany & 22.7 & 35.0 & 33.2 & 26.8 \\
France & 19.0 & 15.2 & 21.9 & 19.5 \\
Italy & 8.9 & 15.2 & 12.0 & 12.5 \\
Netherlands & 6.3 & 7.3 & 7.5 & 9.1 \\
Spain & 4.2 & 2.0 & 1.6 & 2.1 \\
Belgium & 3.4 & 5.1 & 3.9 & 6.8 \\
Denmark & 2.9 & 2.3 & 2.4 & 3.7 \\
Greece & 1.0 & 0.7 & 1.0 & 1.1 \\
Ireland & 0.7 & 0.2 & 0.5 & 0.6 \\
Portugal & 0.3 & 0.3 & 0.1 & 0.1 \\
Luxembourg & 0.0 & 0.0 & 0.0 & 0.0 \\
\hline
\end{tabular}


Table 2

Relative strength $\left(\mathrm{r}_{\mathrm{ik}}\right)$ of co-authorship links of Eastern Middle-European countries with the European Community, 1980-1984 and 1985-1989

\begin{tabular}{lrrrrrrr}
\hline Country & \multicolumn{2}{c}{$\mathbf{r}_{\mathbf{i k}}(\mathrm{HUN})$} & \multicolumn{2}{c}{$\mathbf{r}_{\mathbf{i k}}(\mathrm{POL})$} & \multicolumn{2}{c}{$\mathbf{r}_{\mathbf{i k}}(\mathrm{CZE})$} \\
\hline & & & & & & \\
& & & & & & \\
UK & 0.30 & $85-89$ & 0.40 & 0.50 & 0.61 & 0.19 & 0.29 \\
Germany & 0.56 & 1.10 & 0.97 & 1.70 & 0.22 & 0.41 \\
France & 0.31 & 0.48 & 0.84 & 1.10 & 0.26 & 0.33 \\
Italy & 0.38 & 0.68 & 0.59 & 0.95 & 0.24 & 0.31 \\
Netherlands & 0.30 & 0.37 & 0.47 & 0.68 & 0.21 & 0.27 \\
Spain & 0.02 & 0.18 & 0.10 & 0.19 & 0.03 & 0.09 \\
Belgium & 0.31 & 0.33 & 0.30 & 0.53 & 0.20 & 0.29 \\
Denmark & 0.21 & 0.11 & 0.20 & 0.33 & 0.09 & 0.20 \\
Greece & 0.03 & 0.12 & 0.02 & 0.34 & 0.04 & 0.10 \\
Ireland & 0.00 & 0.04 & 0.07 & 0.13 & 0.04 & 0.05 \\
Portugal & 0.02 & 0.08 & 0.03 & 0.05 & 0.00 & 0.03 \\
Luxembourg & 0.00 & 0.00 & 0.00 & 0.00 & 0.00 & 0.00 \\
\hline
\end{tabular}

In addition to the above data and indicators Figs 1 and 2 show the change of the three countries' publication output and the share of papers co-authored with German scientists between 1980 and 1989. Figure 1 shows a stable publication output of all three countries with very small increments. The only exception is a drastic decrease of Polish publication output in $\mathbf{1 9 8 2}$ which is, however, completely compensated in the subsequent years. Data concerning the absolute publication outputs can be found in Table 3. The rapid increase of cooperations of Hungary and Poland with Germany as well as the moderate cooperation of Czechoslovakia during the whole observation period confirm the corresponding indicator values in Table 2 .

The following part is concerned with the research profile of the studied cooperations with Germany. In order to avoid artefacts it is of particular interest whether cooperation with Germany means a bilateral cooperation or a multilateral one with German participation. Particularly, if the majority of German cooperations would turn out to be only a part of great multinational projects, then the validity of possible conclusions may not always be guaranteed. Figure 3 shows the share of bilateral $v s$. multilateral co-authorships with Germany. The share of purely bilateral cooperations in all cooperations with German participation ranges between $60 \%$ and 90\%. Only the case of Hungary is showing a slight decrease over time. 
W. GLÄNZEL, M. WINTERHAGER: WORLD FLASH ON BASIC RESEARCH

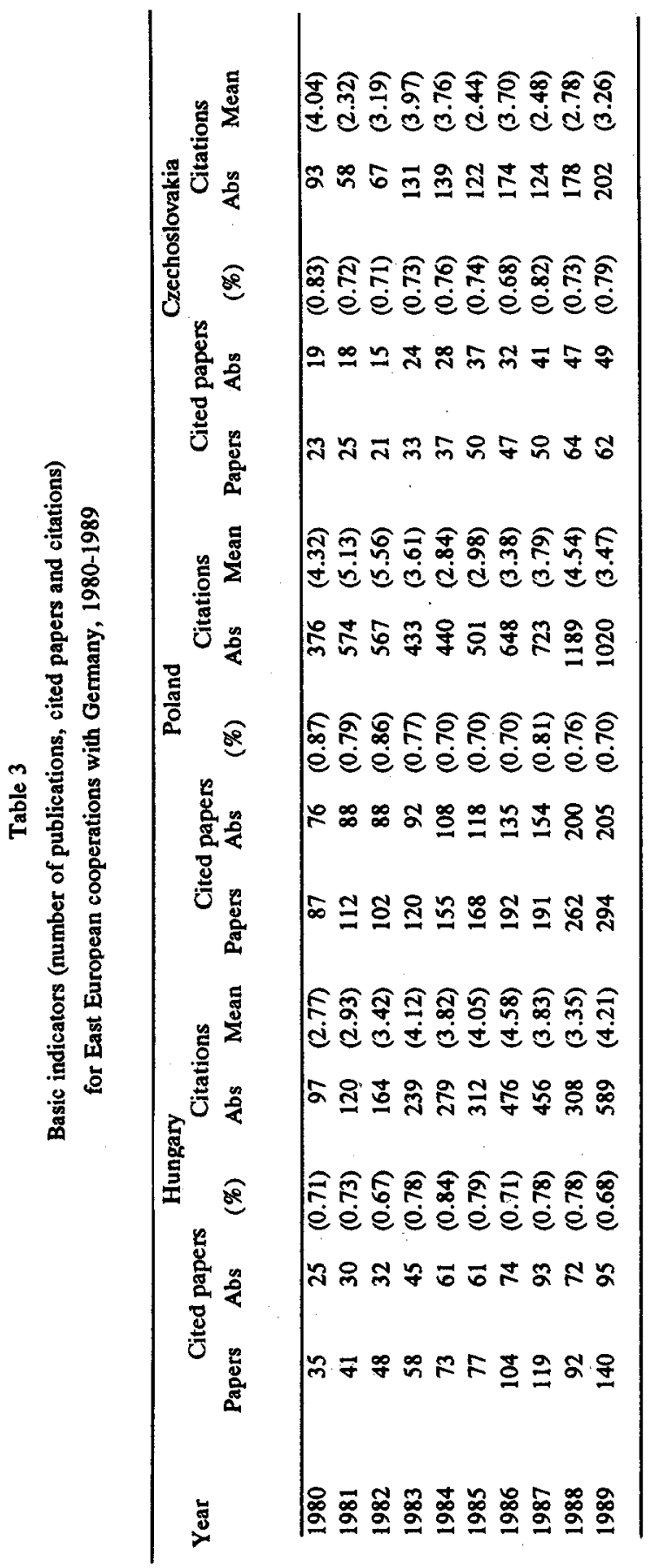




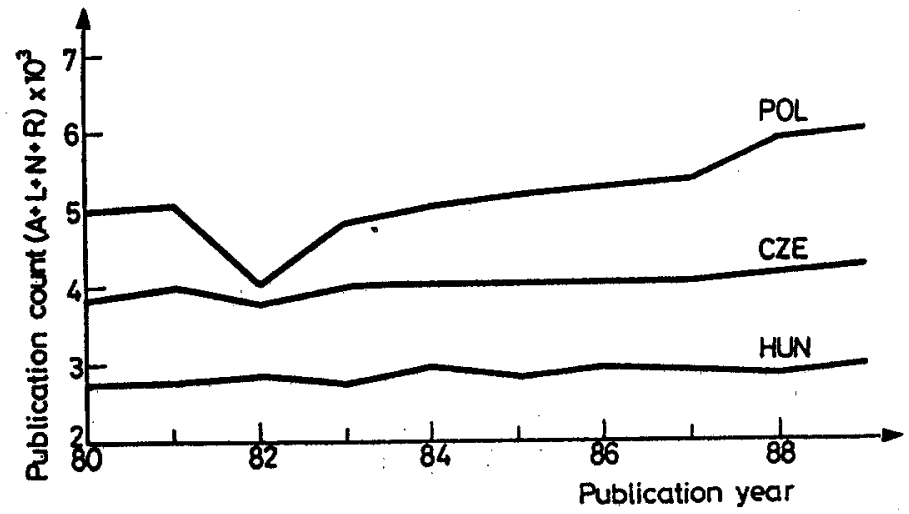

Fig. 1. Publication output of Hungarian, Polish and Czechoslovakian authors, 1980-1989

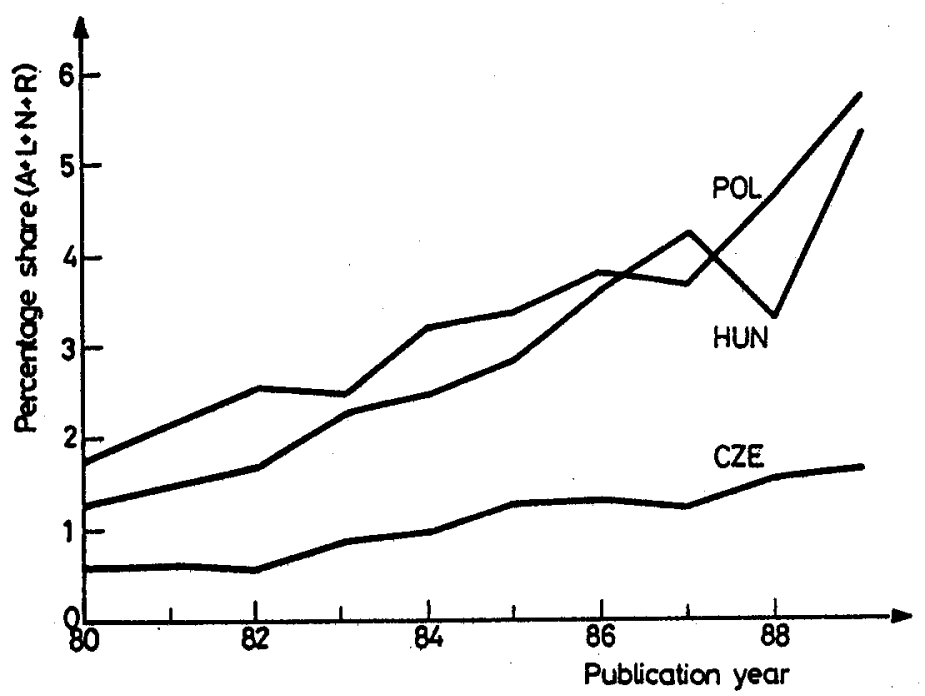

Fig. 2. Percentage share of cooperations with Germany in all fields of the sciences, 1980-1989

If the research profile of Hungarian, Polish and Czechoslovakian cooperations with Germany between 1980 and 1989 is compared with the usual national research profiles of these East European countries (cf. Schubert et al. ${ }^{2}$ ), a remarkable shift from chemistry and engineering to physical sciences can be noticed. This tendency holds for all three countries but especially for Poland where almost $50 \%$ of all papers with German co-authors are concerned with physical sciences. Figure 4 presents the distribution of papers with German co-authors by five major fields. The deviation of these research profiles from the usual national ones becomes clearer if purely bilateral vs. multilateral projects with German participation are considered 
separately. The data are given in Table 4 . The great portion of physics research in multinational projects is of course not surprising. Its overwhelming share in multilateral publications of German and Polish co-authors (more then 70\%) is, however, noticable. The contrary tendency in Czechoslovakian cooperations is rather unexpected. The portion of physics papers shrinks in multinational research as compared with purely bilateral projects wheras the number of publications in the life sciences is growing. More then $50 \%$ of all multilateral papers with German coauthors come from the life sciences. Finally an interesting detail: 34 out of 60 multinational papers published by Hungarian and German authors in 1986 and 1987 were concerned with Comet Halley.

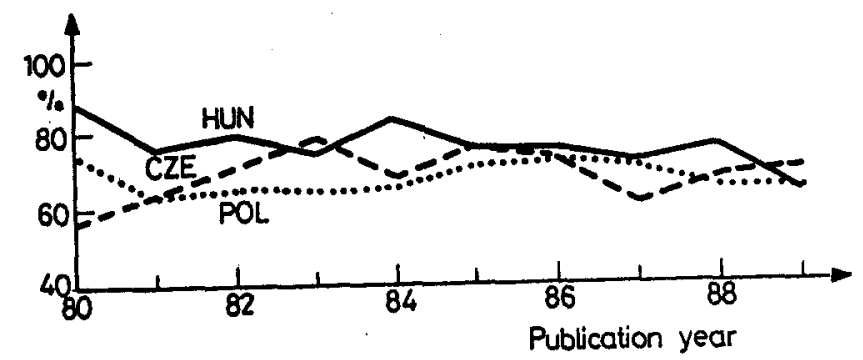

Fig. 3. Share of Hungarian-German, Polish-German and Czechoslovakian-German bilateral papers in all Hungarian, Polish and Czechoslovakian cooperations with German participation, 1980-1989

Table 4

Distribution of purely bilateral (b) and multilateral (m) cooperations with Germany, 1980-1989

\begin{tabular}{lrrrrrrrr}
\hline \multirow{2}{*}{ Major field } & \multicolumn{2}{c}{ Hungary } & & \multicolumn{2}{c}{ Poland } & & \multicolumn{2}{c}{ Czechoslovakia } \\
& $\mathrm{b}$ & $\mathrm{m}$ & & $\mathrm{b}$ & $\mathrm{m}$ & & $\mathrm{b}$ & $\mathrm{m}$ \\
\hline Life sciences & 46.9 & 48.8 & & 35.7 & 15.9 & 40.3 & 52.7 \\
Physical sciences & 21.8 & 28.8 & 36.5 & 70.7 & 31.8 & 27.1 \\
Chemistry & 22.0 & 16.1 & 14.9 & 8.0 & 18.7 & 13.2 \\
Engineering & 5.3 & 2.4 & 10.7 & 4.0 & 4.9 & 4.7 \\
Mathematics & 4.0 & 3.9 & 2.3 & 1.4 & 4.2 & 2.3 \\
Total & 100.0 & 100.0 & 100.0 & 100.0 & 100.0 & 100.0 \\
\hline
\end{tabular}



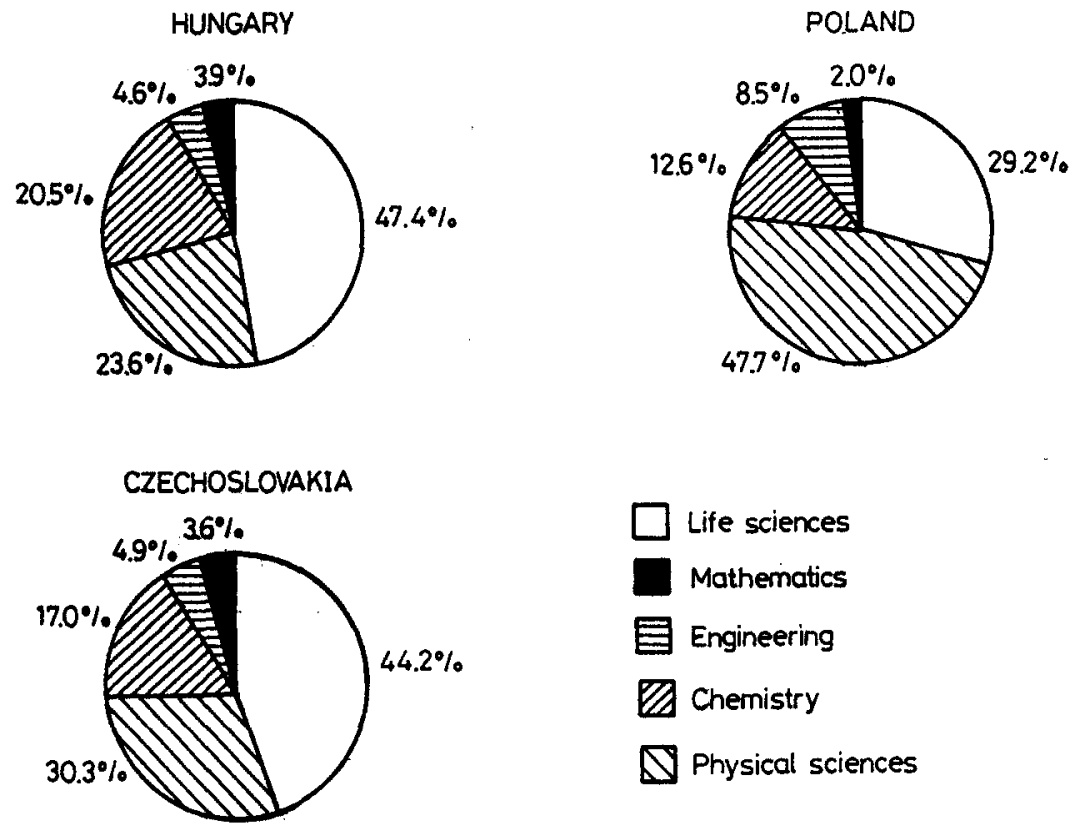

Fig. 4. Distribution of Hungarian-German, Polish-German and Czechoslovakian-German papers by majors fields, 1980-1989

A short discussion of the citation rates of the papers co-authored with German scientists have received will conclude this study. A citation period of three years (publication year and the two subsequent years) seems on the macro-level and in consideration of the above research profiles long enough to guarantee valid results (cf. Glänzel and Schoepflin ${ }^{3}$ ). The annual mean citation rates range between 3 and 5. This corresponds to a much higher standard than that of the East European countries. In the second half of the decade Hungarian-German papers had the highest citation impact, followed by Polish-German cooperations. The Czechoslovakian publications have the least impact of the group. Because of the great yearly fluctuation a statistical reliability test is omitted. The huge impact of Polish cooperations in 1981 and 1982 is, however, striking, especially if this phenomenon is compared to the above mentioned "publication valley" in 1982 (see Fig. 1 and Table 3). The very low portion of uncited papers in all three cooperation groups is remarkable. The relative frequency of those papers which have not received any citations during the first three years is relatively stable and ranges between $13 \%$ 
and $33 \%$. The great impact as well as the small portion of uncited papers seems to comfirm the greater effort of bi- and multinational research.

This study is in part supported by an Alexander von Humboldt Research Fellowship. The first author wishes to ackowlegde the support.

\section{References}

1. A. SCHUbERT, T. BRAUN, International collaboration in the sciences, 1981-1985, Scientometrics 19 (1990) 3-10.

2. A. SCHUBERT, W. GLÄNZEL, T. BRAUN, Scientometric datafiles. A comprehensive set of indicators on 2649 journals and 96 countries in all major science fields and subfields, 1981-1985, Scientometrics 16 (1989) 3-478.

3. W. GLÄNZEL, U. SCHOEPFLIN, A bibliometric study on aging and reception processes of scientific literature, submitted to Journal of Information Sciences. 